\title{
Activation of the surface dark-layer to enhance upconversion in a thermal field
}

\author{
Jiajia Zhou ${ }^{\star}$, Shihui Wen ${ }^{\circ}$, Jiayan Liao, Christian Clarke, Sherif Abdulkader Tawfik, Wei Ren, \\ Chao Mi, Fan Wang (iD and Dayong Jin (1)*
}

\begin{abstract}
Thermal quenching, in which light emission experiences a loss with increasing temperature, broadly limits luminescent efficiency at higher temperature in optical materials, such as lighting phosphors ${ }^{1-3}$ and fluorescent probes ${ }^{4-6}$. Thermal quenching is commonly caused by the increased activity of phonons that leverages the non-radiative relaxation pathways. Here, we report a kind of heat-favourable phonons existing at the surface of lanthanide-doped upconversion nanomaterials to combat thermal quenching. It favours energy transfer from sensitizers to activators to pump up the intermediate excitedstate upconversion process. We identify that the oxygen moiety chelating $\mathrm{Yb}^{3+}$ ions, [Yb...0], is the key underpinning this enhancement. We demonstrate an approximately 2,000-fold enhancement in blue emission for $9.7 \mathrm{~nm} \mathrm{Yb}^{3+}-\mathrm{Tm}^{3+}$ co-doped nanoparticles at $453 \mathrm{~K}$. This strategy not only provides a powerful solution to illuminate the dark layer of ultra-small upconversion nanoparticles, but also suggests a new pathway to build high-efficiency upconversion systems.
\end{abstract}

A phonon represents an excited quantum state of vibration within a material's elastic structure. Although the ensemble frequencies and behaviours of phonons within many bulk materials have been well studied ${ }^{7}$, understanding of the difference and interactions of phonons at the surface of nanomaterials is quite limited. However, it has been generally believed that an increase in the surface-to-volume ratio will introduce more quenching factors from the vibrating surface environment so that the quenching of luminescence becomes dominant ${ }^{8,9}$.

This study focuses on investigating the roles of phonons, generated at the surface of lanthanide-doped upconversion nanomaterials, in facilitating energy transfer (ET). By up-converting low-energy photons into high-energy visible emission, upconversion nanoparticles (UCNPs) have attracted much attention in a wide range of applications, such as fluorescence microscopy ${ }^{10,11}$, nanoscale thermometry ${ }^{6,12}$, photodynamic therapy ${ }^{13}$, optogenetics ${ }^{14}$, security inks ${ }^{15,16}$, photovoltaic converters ${ }^{17}$ and three-dimensional volumetric displays ${ }^{18,19}$.

While conventionally vibrating surface molecules are believed to quench the luminescence of nanoparticles ${ }^{11,20}$, here we find the moiety of surface molecules that chelate the exposed surface ions, in particular the sensitizer ions $\left(\mathrm{Yb}^{3+}\right)$, generates surface phonons. When increasing the temperature, more surface phonons will become active to be locally coupled to $\mathrm{Yb}^{3+}$. That is, the [ $\left.\mathrm{Yb} \cdots \mathrm{O}\right]$ complexes assist stepwise transfer of the trapped energy onto the scaffold energy levels of the $\mathrm{Tm}^{3+}$ activators, which eventually produces much brighter up-converted emissions, as illustrated in Fig. 1. This process can help nanoparticles overcome the thermal quenching effect, and the brightness of UCNPs can be increased by orders of magnitude at high temperatures.

Fourier-transform infrared spectroscopy (FTIR) and Raman spectrometry measurements, shown in Fig. 1, reveal that the long chain of oleic acids contains multiple frequencies of vibrating states of phonons; for example, the symmetric and asymmetric -COO stretches at $1,454 \mathrm{~cm}^{-1}$ and $1,558 \mathrm{~cm}^{-1}$, and the symmetric and asymmetric $-\mathrm{CH}_{2}-1-\mathrm{CH}_{3}$ stretches at $2,856 \mathrm{~cm}^{-1}$ and $2,925 \mathrm{~cm}^{-1} 21$. The frequencies $247 \mathrm{~cm}^{-1}, 296 \mathrm{~cm}^{-1}$ and $355 \mathrm{~cm}^{-1}$ belong to the phonon frequencies of the host fluoride crystal while the frequencies $471 \mathrm{~cm}^{-1}, 491 \mathrm{~cm}^{-1}, 559 \mathrm{~cm}^{-1}$ and $620 \mathrm{~cm}^{-1}$ should come from the $[\mathrm{Yb} / \mathrm{Y} / \mathrm{Tm} \cdots \mathrm{O}]$ coordination, although there is limited knowledge reported from the literature ${ }^{22,23}$. We therefore perform a calculation and find that these vibration frequencies fall within the ranges $510-560 \mathrm{~cm}^{-1}$ and $117-255 \mathrm{~cm}^{-1}$ (see Supplementary Fig. 4 and Table 1). The low-frequency phonons $\left(<355 \mathrm{~cm}^{-1}\right)$, including the host vibration modes, make only a small contribution to ET at high temperature, while the high-frequency phonons related to the other stretches of surface molecules $\left(>1,000 \mathrm{~cm}^{-1}\right)$ are far away from, and cannot be locally coupled with, the excited state $\mathrm{Yb}^{3+}$.

Figure 2a illustrates that surface phonons not only facilitate ET from the $\mathrm{Yb}^{3+}:{ }^{2} \mathrm{~F}_{5 / 2}$ to the $\mathrm{Tm}^{3+}:{ }^{3} \mathrm{H}_{5}$ level as the prime ET step, but also supplement the energy mismatch by enabling non-radiative relaxations-for example, ${ }^{3} \mathrm{H}_{5} \Rightarrow{ }^{3} \mathrm{~F}_{4},{ }^{3} \mathrm{~F}_{2,3} \Rightarrow{ }^{3} \mathrm{H}_{4}$, of the excited $\mathrm{Tm}^{3+}$ ions-so that multiple quanta of phonon-modulated sensitized photons will be stepwise up-converted onto the scaffold excited states of $\mathrm{Tm}^{3+}$. This indicates that the process to up-convert photons onto higher excited states of $\mathrm{Tm}^{3+}$ demands greater participation of the surface phonons ${ }^{24}$. Therefore, when increasing the temperature, the upconversion emissions from higher levels are more obviously enhanced than those from lower levels (see Fig. 2c). Figure $2 \mathrm{~b}$ shows that a higher concentration of $\mathrm{Yb}^{3+}$ provides an increased $[\mathrm{Yb} \cdots \mathrm{O}]$ ligand-cation interaction that benefits the enhancement.

This observation also suggests that the underpinning mechanism based on surface phonons should be broadly applicable to other typical ET systems, which is experimentally verified (see Fig. 2e). Moreover, by comparing the degrees of energy level mismatches between sensitizers and different activators, as shown in Fig. 2d, we find the maximum enhancement factors of surface-phononenhanced upconversion strongly follow the degree of energy mismatch in the order $\Delta E_{\text {Down: Yb-Tm }}>\Delta E_{\text {Down: Yb-Ho }}>\Delta E_{\mathrm{Up} \text { : Yb-Er }}$ as shown in Fig. $2 \mathrm{e}$ and $\mathrm{f}$. It is worth mentioning here that significant upconversion emission enhancement is achieved for UCNPs with sizes even larger than $40 \mathrm{~nm}$, which rules out the possible mechanism being described as the release effect of 'phonon confinement' ${ }^{25}$, 


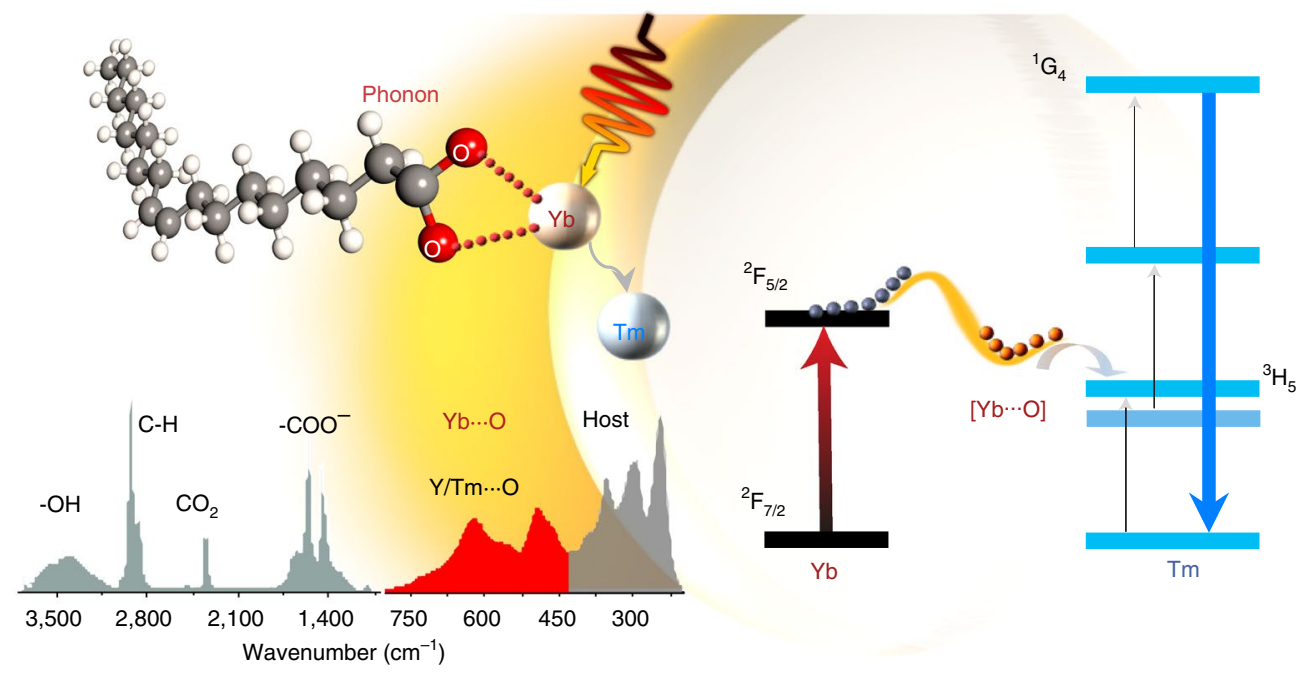

Fig. 1 | Schematic illustration of the surface-phonon-enhanced upconversion process. Different from the conventional upconversion process, [Yb $\ldots . \mathrm{O}]$ coordination generates surface phonons and participates in the upconversion process, so that the excited state population of sensitizers, defined by the narrow band of the ${ }^{2} \mathrm{~F}_{7 / 2}$ level of $\mathrm{Yb}^{3+}$, will be modulated to form the broad band of a virtual state. This improves the degree of energy transfer matching between $\mathrm{Yb}\left({ }^{2} \mathrm{~F}_{7 / 2}\right)$ and $\mathrm{Tm}\left({ }^{3} \mathrm{H}_{5}\right)$ to achieve a higher energy transfer efficiency. Inset data show the vibrational modes of oleate-capped nanocrystals through FTIR $\left(1,000-3,800 \mathrm{~cm}^{-1}\right)$ and Raman $\left(200-800 \mathrm{~cm}^{-1}\right)$ measurements.

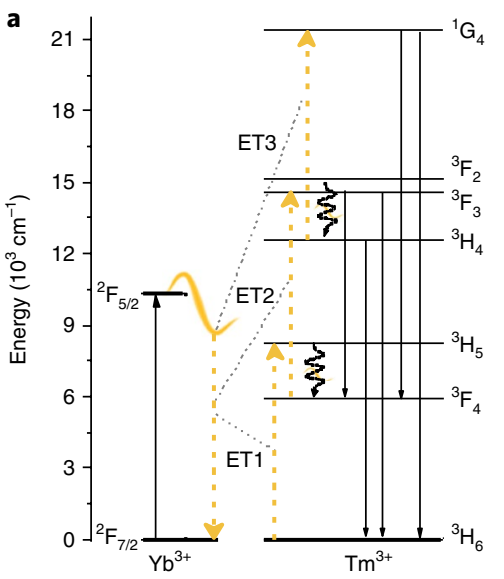

d

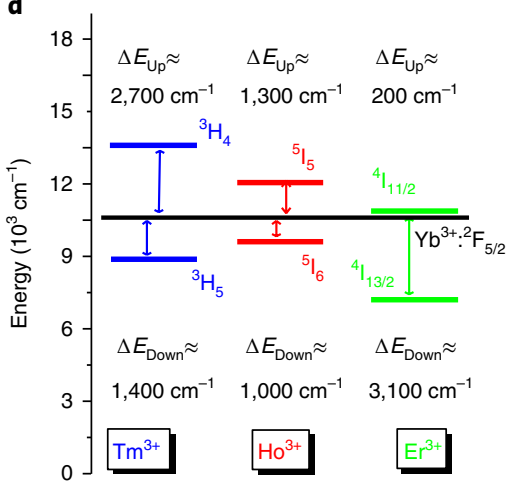

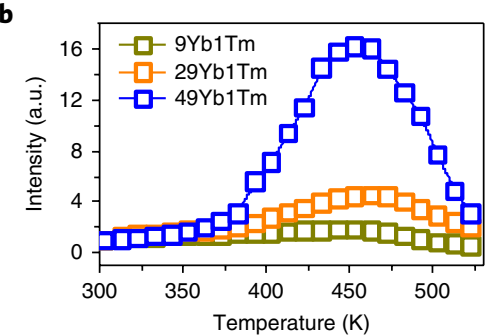
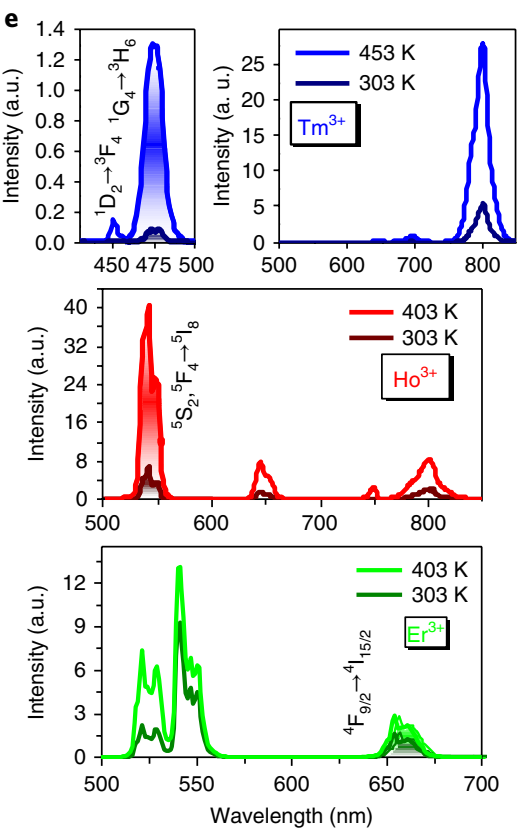

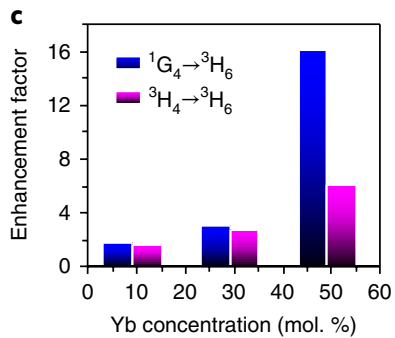

f

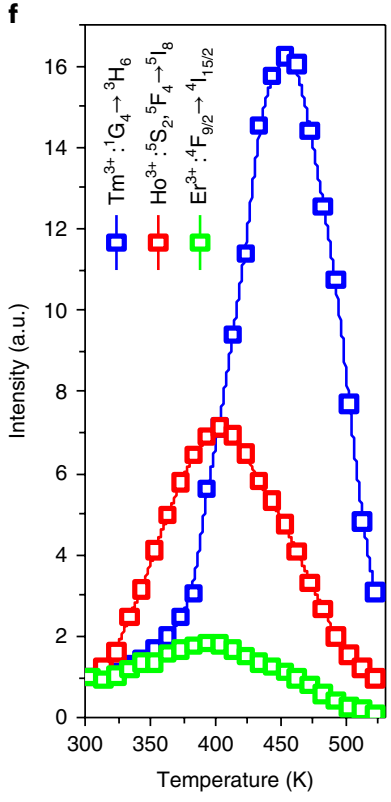

Fig. 2 | Surface-phonon-enhanced upconversion in different sensitizer-activator systems. $\mathbf{a}, \mathrm{Yb}^{3+}$ and $\mathrm{Tm}^{3+}$ energy level diagram shows surface phonons participating in upconversion. $\mathbf{b}$, Intensity of the $\mathrm{Tm}^{3+}{ }^{1} \mathrm{G}_{4} \rightarrow{ }^{3} \mathrm{H}_{6}$ transitions depends on both temperature and $\mathrm{Yb}^{3+}$ concentrations. c, Maximum enhancement factors of $\mathrm{Tm}^{3+}:{ }^{3} \mathrm{H}_{4} \rightarrow{ }^{3} \mathrm{H}_{6}$ transitions compared with those of ${ }^{1} \mathrm{G}_{4} \rightarrow{ }^{3} \mathrm{H}_{6}$ from nanoparticles with different $\mathrm{Yb}^{3+}$ concentrations. d, Approximate energy gaps between the excited states of the sensitizer $\mathrm{Yb}^{3+}$ and nearby typical activators. e, Emission spectra of $\beta-\mathrm{NaYF}_{4}: 49 \% \mathrm{Yb}^{3+}-1 \% \mathrm{X}\left(\mathrm{X}=\mathrm{Tm}^{3+}, \mathrm{Ho}^{3+}\right.$ and $\left.\mathrm{Er}^{3+}\right)$ nanoparticles at $303 \mathrm{~K}$ and a high temperature ( $403 \mathrm{~K}$ for $\mathrm{Er}^{3+}$ and $\mathrm{Ho}^{3+}$, and $453 \mathrm{~K}$ for $\mathrm{Tm}^{3+}$ ). f, Temperature-dependent intensities of $\mathrm{Tm}^{3+}:{ }^{1} \mathrm{G}_{4} \rightarrow{ }^{3} \mathrm{H}_{6}, \mathrm{Ho}^{3+}:{ }^{5} \mathrm{~S}_{2}$, ${ }^{5} \mathrm{~F}_{4} \rightarrow{ }^{5} \mathrm{I}_{8}$ and $\mathrm{Er}^{3+}:{ }^{4} \mathrm{~F}_{9 / 2} \rightarrow{ }^{4} \mathrm{I}_{15 / 2}$ transitions. (For sample morphologies of $\mathbf{b}$ and $\mathbf{e}$, see Supplementary Fig. $1.980 \mathrm{~nm}$ laser excitation, at $0.5 \mathrm{~W} \mathrm{~cm}^{-2}$ ). 

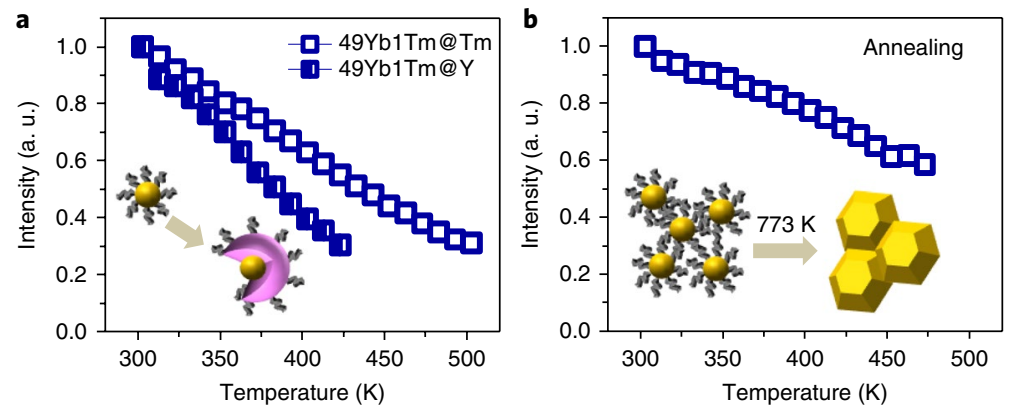

d
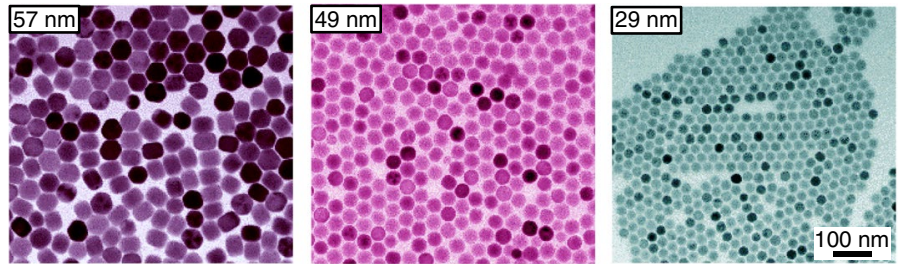

f

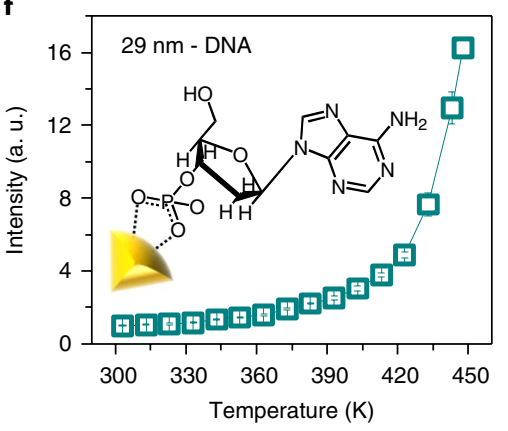

g

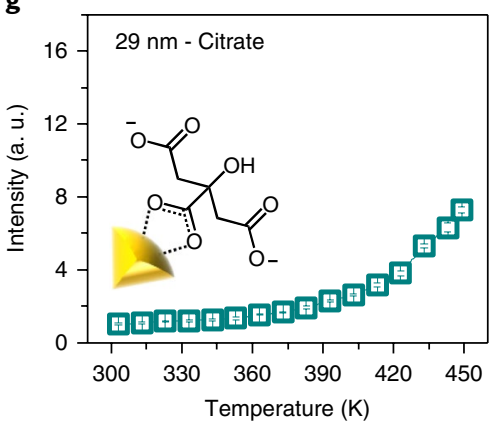

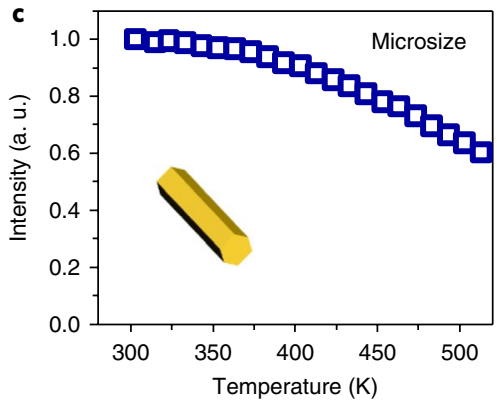

e

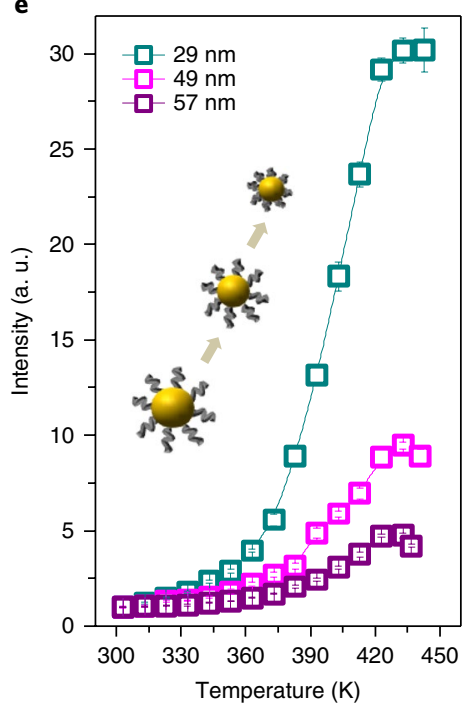

Fig. 3 | Surface engineering to investigate surface-phonon-enhanced upconversion. a-c, The temperature-dependent intensity changes of $\beta$-NaYF $\mathrm{F}_{4}: 49 \%$ $\mathrm{Yb}^{3+}-1 \% \mathrm{Tm}^{3+} @ \beta-\mathrm{NaYF}_{4}: 1 \% \mathrm{Tm}^{3+}$ and $\beta-\mathrm{NaYF}_{4}: 49 \% \mathrm{Yb}^{3+}-1 \% \mathrm{Tm}^{3+} @ \mathrm{NaYF}_{4}$ core-shell nanoparticles (core size of $29 \mathrm{~nm}$ and shell thickness of $\sim 7.5 \mathrm{~nm}$ ) (a), annealed (at $773 \mathrm{~K}_{1} \mathrm{~h}$ ) $\beta-\mathrm{NaYF}_{4}: 49 \% \mathrm{Yb}^{3+}-1 \% \mathrm{Tm}^{3+}$ nanoparticles (b), and $\beta-\mathrm{NaYF}_{4}: 49 \% \mathrm{Yb}^{3+}-1 \% \mathrm{Tm}^{3+}$ micrometre-sized rods $(2 \mu \mathrm{m}$ in length and $380 \mathrm{~nm}$ in diameter) (c). d,e, Size-dependent surface-phonon-enhanced upconversion luminescence $\left(\mathrm{Tm}^{3+}:{ }^{1} \mathrm{G}_{4} \rightarrow{ }^{3} \mathrm{H}_{6}\right)$ of $\beta-\mathrm{NaYF}_{4}: 49 \% \mathrm{Yb}^{3+}-1 \% \mathrm{Tm}^{3+}$ nanoparticles in a thermal field (e) with TEM images (d). f,g, Hydrophilic nanoparticles ( $29 \mathrm{~nm} \beta-\mathrm{NaYF}_{4}: 49 \% \mathrm{Yb}^{3+}-1 \% \mathrm{Tm}^{3+}$ ) with surface-capped DNA (f) and citrate (g) maintain upconversion enhancement at high temperatures. (For sample morphologies of a-c, see Supplementary Fig. 2. $980 \mathrm{~nm}$ laser excitation, at $\left.0.5 \mathrm{~W} \mathrm{~cm}^{-2}\right)$.

which should only happen at extremely low temperature for small nanoparticles ${ }^{22,26,27}$.

To quantitatively understand the temperature-dependent luminescent enhancement and its relationship with $\Delta E$, we monitor the intensity variations of $475 \mathrm{~nm}$ emissions $\left(\mathrm{Tm}^{3+}:{ }^{1} \mathrm{G}_{4} \rightarrow\right.$ $\left.{ }^{3} \mathrm{H}_{6}\right), 545 \mathrm{~nm}$ emissions $\left(\mathrm{Ho}^{3+}:{ }^{5} \mathrm{~S}_{2},{ }^{5} \mathrm{~F}_{4} \rightarrow{ }^{5} \mathrm{I}_{8}\right)$, and $654 \mathrm{~nm}$ emissions $\left(\mathrm{Er}^{3+}:{ }^{4} \mathrm{~F}_{9 / 2} \rightarrow{ }^{4} \mathrm{I}_{15 / 2}\right)$ by fine tuning the temperature from $303 \mathrm{~K}$ to $523 \mathrm{~K}$, as shown in Fig. 2f. Clearly, in the medium-temperature range, the as-discovered surface phonons can overcome the thermal quenching effects, but extremely high temperature will promote the population of other deleterious phonons at different vibration frequencies, from, for example, host lattice, internal/ surface crystalline defects, and surface chemical bonds, that commonly exist in luminescent nanomaterials. The earlier and rapid rise of upconversion enhancement at relatively lower temperature for $\mathrm{Ho}^{3+}$ nanoparticles suggests its lower requirement in temperature activation energy as a result of a smaller energy mismatch between $\mathrm{Yb}^{3+}$ and $\mathrm{Ho}^{3+}\left(\Delta E_{\text {Down: } \mathrm{Yb}-\mathrm{Ho}} \approx 1,000 \mathrm{~cm}^{-1}\right)$ compared to $\mathrm{Tm}^{3+}$ $\left(\Delta E_{\mathrm{Down}: \mathrm{Yb}-\mathrm{Tm}} \approx 1,400 \mathrm{~cm}^{-1}\right)$. (Note: the temperature response for $\mathrm{Er}^{3+}$ is affected by the thermal coupling effect ${ }^{28}$.)

To further confirm the important role of oxygen moiety chelating $\mathrm{Yb}^{3+}$ sensitizers in generating surface phonons that enhance the upconversion efficiency in a thermal field, we also collect evidence by reverse logic by checking materials without $[\mathrm{Yb} \ldots \mathrm{O}]$ coordination on the surface. Figure $3 \mathrm{a}-\mathrm{c}$ shows the different design strategies for isolating $\mathrm{Yb}^{3+}$ ions from the surface with an inert shell or a layer with singly doped $1 \mathrm{~mol} \% \mathrm{Tm}^{3+}$, damaging the surface ligands by a heat annealing process, and growing bulk (micro rods) upconversion materials with a negligible amount of surface ligands, respectively. The reduction in [ $\mathrm{Yb}$...O ]-induced phonons in the annealing process can be qualitatively monitored by Raman spectroscopy measurements (Supplementary Fig. 3). All three cases result only in thermal quenching.

Figure 3e (TEM images in panel d) further shows that increasing the surface-to-volume ratio by decreasing the size of the nanoparticles will introduce greater $[\mathrm{Yb} \ldots \mathrm{O}]$ coordination to participate in upconversion, and result in increased amplification of the enhancement at high temperature, with a new record of 30-fold enhancement achieved from $29 \mathrm{~nm}$ spherical nanoparticles. As a further proof, when the as-synthesized UCNPs are transferred from the hydrophobic (in-situ formed oleate) to the hydrophilic (for example, citrate, DNA) surface, through a ligand exchange protocol ${ }^{29}$, as long as the $[\mathrm{Yb} \cdots \mathrm{O}]$ interface property can be retained, upconversion enhancements are observed (shown in Fig. $3 \mathrm{f}$ and g).

By confirming that the thermal-field-enhanced upconversion is due to surface phonons, we further apply this discovery to improve the brightness of sub-10 nm ultra-small UCNPs, which has become a hot research topic ${ }^{30}$. Due to their relatively large surface area ${ }^{9,11,31}$, surface vibrations will result in a dark layer $(\sim 1.7 \mathrm{~nm} \text { in thickness })^{11}$. In our case, for a $9.7 \mathrm{~nm} \beta-\mathrm{NaYF}_{4}$ nanoparticle (Fig. $4 \mathrm{a}-\mathrm{c}$ ), the 

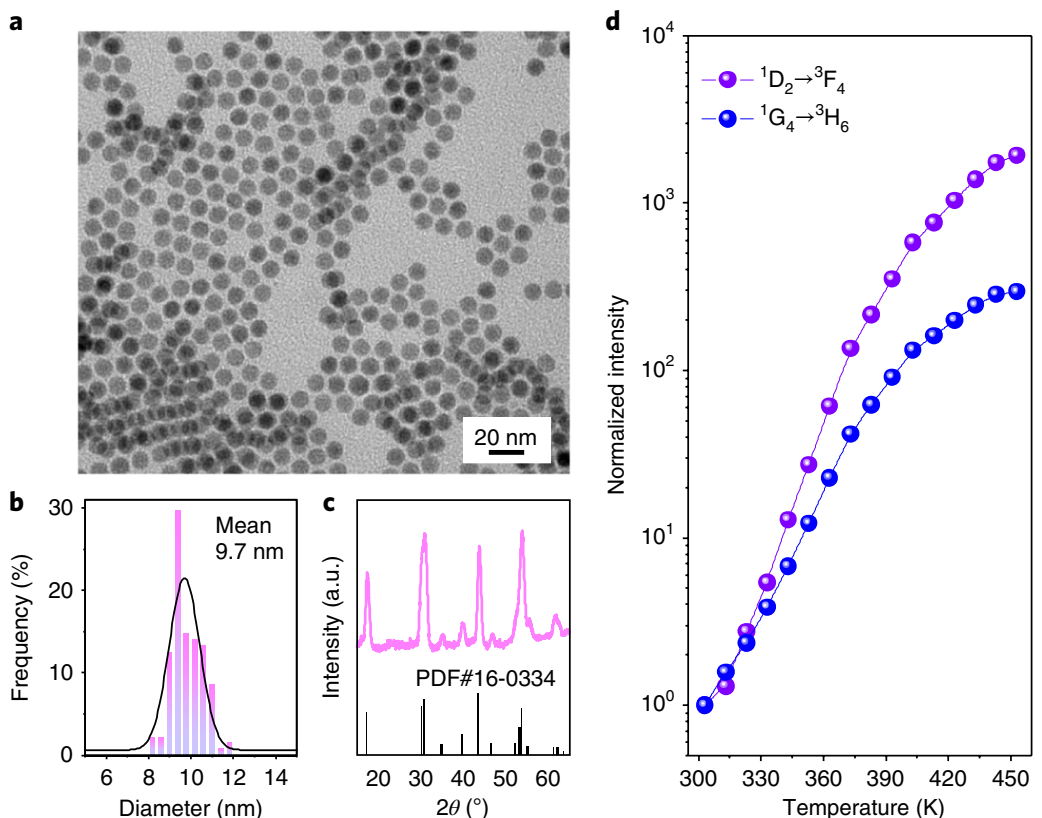

e

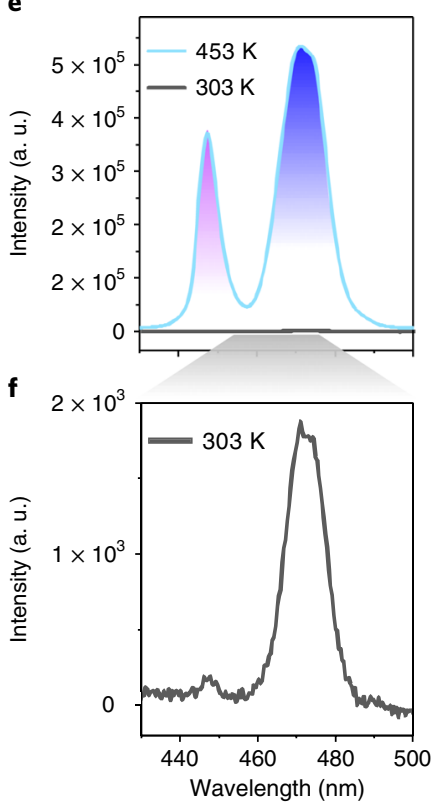

g
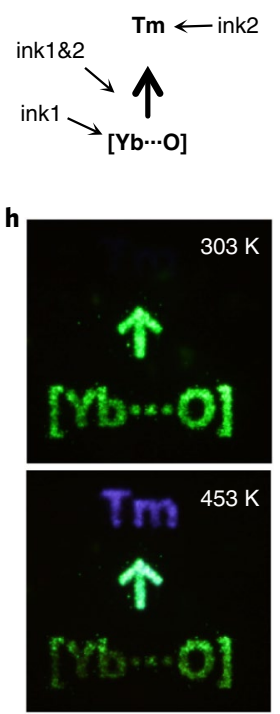

Fig. 4 | Surface phonons significantly enhance the brightness of ultra-small upconversion nanoparticles. a, TEM image of the synthesized sub-10 nm

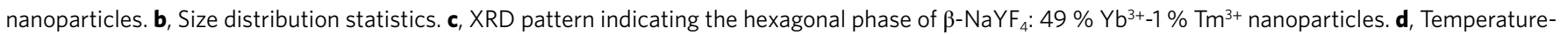
dependent blue emission enhancement. e, Corresponding blue emission spectra at $453 \mathrm{~K}$ and $303 \mathrm{~K}$ conducted in $\mathbf{d}$. ( $980 \mathrm{~nm}$ laser excitation at $10 \mathrm{~W} \mathrm{~cm}^{-2}$ ). $\mathbf{f}$, Enlarged view of the blue emission spectrum at $303 \mathrm{~K}$ (grey line in $\mathbf{e}$ ). $\mathbf{g}, \mathbf{h}$, Temperature-responsive anti-counterfeiting security inks. Printed pattern (g) and output (h). $\left(1 \mathrm{~cm} \times 1 \mathrm{~cm}\right.$ pattern under $980 \mathrm{~nm}$ laser excitation, at $\left.0.7 \mathrm{~W} \mathrm{~cm}^{-2}\right)$.

dark layer occupies up to $72 \%$ of the total volume, and therefore its brightness is significantly low. By increasing the temperature from room temperature to $453 \mathrm{~K}$, surprisingly, we find their blue emissions at $450 \mathrm{~nm}$ and $475 \mathrm{~nm}$, corresponding to the transitions $\mathrm{Tm}^{3+}$ : ${ }^{1} \mathrm{D}_{2} \rightarrow{ }^{3} \mathrm{~F}_{4}$ and ${ }^{1} \mathrm{G}_{4} \rightarrow{ }^{3} \mathrm{H}_{6}$, are enhanced by factors of 2,000 and 300 , respectively (Fig. $4 \mathrm{~d}-\mathrm{f}$ ). The exceptional luminescence enhancement at high temperature provides a new type of security ink that is responsive to the temperature change. Figure $4 \mathrm{~g}-\mathrm{h}$ illustrates a covert image printed on paper by an inkjet printer using the thermally enhanced $9.7 \mathrm{~nm}$ nanoparticles (UCNP ink 2) and the conventional $\mathrm{NaYF}_{4}: 20 \% \mathrm{Yb}^{3+}-2 \% \mathrm{Er}^{3+}$ nanoparticles (UCNP ink 1). On increasing the temperature to $453 \mathrm{~K}$ and under $980 \mathrm{~nm}$ illumination, a blue character 'Tm' clearly appears against a decreased green '[Yb...O]', and the arrow ' $\uparrow$ ' printed by both inks shows up in whitish green due to the enhanced blue emission.

To estimate the upconversion efficiency of [ $\mathrm{Yb} \cdots \mathrm{O}]$ coordination $\rightarrow \mathrm{Tm}^{3+}$ ions, we measure the overall enhancement factors of the $57 \mathrm{~nm}, 49 \mathrm{~nm}, 29 \mathrm{~nm}$ and $9.7 \mathrm{~nm}$ UCNPs across the visible-nearinfrared spectrum (Supplementary Fig. 5). At high temperature, the intensity from the core $\left(\mathrm{NaYF}_{4}: \mathrm{Yb}^{3+}-\mathrm{Tm}^{3+}\right.$ nanocrystals) will drop by approximately $40 \%$, according to Fig. $3 a-c$, while the surface phonons will turn on the inactive $\mathrm{Yb}^{3+}$ and $\mathrm{Tm}^{3+}$ ions within the dark layer $(\sim 1.7 \mathrm{~nm} \text { in thickness })^{11}$, by forming a new sensitizer-activator pair, $[\mathrm{Yb} \cdots \mathrm{O}] \rightarrow \mathrm{Tm}^{3+}$. The overall enhancement factors of $57 \mathrm{~nm}$, $49 \mathrm{~nm}$ and $29 \mathrm{~nm}$ UCNPs suggest that the new upconversion pathway has an efficiency approximately ten times higher than the $\mathrm{Yb}^{3+}$ $\rightarrow \mathrm{Tm}^{3+}$ UCNP system (Supplementary Table 2). The new upconversion pathway for the $9.7 \mathrm{~nm}$ UCNPs shows a larger factor of 26.9 fold, which suggests either the dark layer could be thicker than $1.7 \mathrm{~nm}$ or the surface phonons on the ultra-small UCNPs would further favour more $\mathrm{Tm}^{3+}$ ions in the core area for upconversion. We further compare the overall intensity of $9.7 \mathrm{~nm}$ UCNPs at high temperature and that of the typical $33 \mathrm{~nm} \beta-\mathrm{NaY}_{0.75} \mathrm{Yb}_{0.25} \mathrm{~F}_{4}: 0.003 \mathrm{Tm}$ UCNPs at room temperature that has been reported with an absolute quantum yield of $0.67 \%$ at $10 \mathrm{~W} \mathrm{~cm}^{-2}\left(\right.$ ref. $\left.^{32}\right)$, and find that the sample of $9.7 \mathrm{~nm}$ UCNPs is 5.4 times brighter (Supplementary Figs. 6 and 7). In particular, this process appears to significantly enhance the quantum yield of the blue transitions. The above analysis confirms that the nanoscale surface plays an essential role in turning on the dark layer of inactive sensitizers and activators. More comprehensive characterizations and quantitative assessments are necessary to gain further insights into the phenomena observed in this work.

\section{Methods}

Methods, including statements of data availability and any associated accession codes and references, are available at https://doi. org/10.1038/s41566-018-0108-5.

Received: 19 September 2017; Accepted: 18 January 2018; Published online: 12 February 2018

\section{References}

1. Kim, Y. H. et al. A zero-thermal-quenching phosphor. Nat. Mater. 16, 543-550 (2017).

2. Wang, L. et al. $\mathrm{Ca}_{1-x} \mathrm{Li}_{x} \mathrm{Al}_{1-x} \mathrm{Si}_{1+x} \mathrm{~N}_{3}: \mathrm{Eu}^{2+}$ solid solutions as broadband, color-tunable and thermally robust red phosphors for superior color rendition white light-emitting diodes. Light Sci. Appl. 5, e16155 (2016).

3. Zhu, H. et al. Highly efficient non-rare-earth red emitting phosphor for warm white light-emitting diodes. Nat. Commun. 5, 4312 (2014).

4. Liang, R. et al. A temperature sensor based on CdTe quantum dots-layered double hydroxide ultrathin films via layer-by-layer assembly. Chem. Commun. 49, 969-971 (2013).

5. Liu, D. et al. Emission stability and reversibility of upconversion nanocrystals. J. Mater. Chem. C 4, 9227-9234 (2016).

6. Zhu, X. et al. Temperature-feedback upconversion nanocomposite for accurate photothermal therapy at facile temperature. Nat. Commun. 7, 10437 (2016).

7. Auzel, F. \& Chen, Y. The effective frequency in multiphonon processes: Differences for energy transfers or side-bands and non-radiative decay. J. Lumin. 66, 224-227 (1995).

8. Xue, X. et al. Size-dependent upconversion luminescence and quenching mechanism of $\mathrm{LiYF}_{4}: \mathrm{Er}^{3+} / \mathrm{Yb}^{3+}$ nanocrystals with oleate ligand adsorbed. Opt. Mater. Express 3, 989-999 (2013).

9. Lim, S. F., Ryu, W. S. \& Austin, R. H. Particle size dependence of the dynamic photophysical properties of $\mathrm{NaYF}_{4}$ : $\mathrm{Yb}, \mathrm{Er}$ nanocrystals. Opt. Express 18, 2309-2316 (2010). 
10. Liu, Y. et al. Amplified stimulated emission in upconversion nanoparticles for super-resolution nanoscopy. Nature 543, 229-233 (2017).

11. Gargas, D. J. et al. Engineering bright sub-10-nm upconverting nanocrystals for single-molecule imaging. Nat. Nanotech. 9, 300-305 (2014).

12. Brites, C. D. et al. Instantaneous ballistic velocity of suspended Brownian nanocrystals measured by upconversion nanothermometry. Nat. Nanotech. 11, 851-856 (2016).

13. Xu, J. et al. Near-infrared-triggered photodynamic therapy with multitasking upconversion nanoparticles in combination with checkpoint blockade for immunotherapy of colorectal cancer. ACS Nano 11, 4463-4474 (2017)

14. Wu, X. et al. Dye-sensitized core/active shell upconversion nanoparticles for optogenetics and bioimaging applications. ACS Nano 10, 1060-1066 (2016).

15. Zhao, J. et al. Single-nanocrystal sensitivity achieved by enhanced upconversion luminescence. Nat. Nanotech. 8, 729-734 (2013).

16. Lu, Y. et al. Tunable lifetime multiplexing using luminescent nanocrystals. Nat. Photon. 8, 32-36 (2014).

17. Zou, W. et al. Broadband dye-sensitized upconversion of near-infrared light. Nat. Photon. 6, 560-564 (2012)

18. Wang, F. et al. Simultaneous phase and size control of upconversion nanocrystals through lanthanide doping. Nature 463, 1061-1065 (2010).

19. Deng, R. et al. Temporal full-colour tuning through non-steady-state upconversion. Nat. Nanotech. 10, 237-242 (2015).

20. Wu, S., Ning, Y., Chang, J. \& Zhang, S. Upconversion photoluminescence enhancement and modulation of $\mathrm{NaYF}_{4}$ : $\mathrm{Yb}$, Er through using different ligands. J. Lumin. 143, 492-497 (2013).

21. Bogdan, N., Vetrone, F., Ozin, G. A. \& Capobianco, J. A. Synthesis of ligand-free colloidally stable water dispersible brightly luminescent lanthanide-doped upconverting nanoparticles. Nano Lett. 11, 835-840 (2011).

22. Shan, J., Uddi, M., Yao, N. \& Ju, Y. Anomalous Raman scattering of colloidal $\mathrm{Yb}^{3+}, \mathrm{Er}^{3+}$ codoped $\mathrm{NaYF}_{4}$ nanophosphors and dynamic probing of the upconversion luminescence. Adv. Funct. Mater. 20 3530-3537 (2010).

23. Panitz, J.-C., Mayor, J.-C., Grob, B. \& Durisch, W. A Raman spectroscopic study of rare earth mixed oxides. J. Alloy Compd. 303, 340-344 (2000).

24. Levy, E. S. et al. Energy-looping nanoparticles: harnessing excited-state absorption for deep-tissue imaging. ACS Nano 10, 8423-8433 (2016).

25. Li, D., Shao, Q., Dong, Y. \& Jiang, J. Anomalous temperature-dependent upconversion luminescence of small-sized $\mathrm{NaYF}_{4}: \mathrm{Yb}^{3+}, \mathrm{Er}^{3+}$ nanoparticles. J. Phys. Chem. C 118, 22807-22813 (2014).

26. Liu, G. et al. Confinement of electron-phonon interaction on luminescence dynamics in nanophosphors of $\mathrm{Er}^{3+}: \mathrm{Y}_{2} \mathrm{O}_{2}$ S. J. Phys. Chem. B 171, 123-132 (2003).
27. Wang, F., Wang, J. \& Liu, X. Direct evidence of a surface quenching effect on size-dependent luminescence of upconversion nanoparticles. Angew. Chem. Int Ed. Engl. 49, 7456-7460 (2010).

28. Vetrone, F. et al. Temperature sensing using fluorescent nanothermometers. ACS Nano 4, 3254-3258 (2010).

29. $\mathrm{Lu}$, J. et al. One-step protein conjugation to upconversion nanoparticles. Anal. Chem. 87, 10406-10413 (2015).

30. Zheng, W. et al. Sub-10 nm lanthanide-doped $\mathrm{CaF}_{2}$ nanoprobes for time-resolved luminescent biodetection. Angew. Chem. Int Ed. 52, 6671-6676 (2013).

31. Zhao, J. et al. Upconversion luminescence with tunable lifetime in $\mathrm{NaYF}_{4}: \mathrm{Yb}, \mathrm{Er}$ nanocrystals: role of nanocrystal size. Nanoscale $\mathbf{5}$, 944-952 (2013)

32. Liu, H. et al. Balancing power density based quantum yield characterization of upconverting nanoparticles for arbitrary excitation intensities. Nanoscale 5 , 4770-4775 (2013)

\section{Acknowledgements}

This project is primarily supported by the Australian Research Council (ARC) Discovery Early Career Researcher Award Scheme (J.Z., DE180100669), Chancellor's Postdoctoral Fellowship Scheme at the University of Technology Sydney (J.Z.), and ARC Future Fellowship Scheme (D.J., FT 130100517).

\section{Author contributions}

J.Z. and D.J. conceived the project and designed the experiments; S.W., J.L., and J.Z. conducted synthesis; C.C. and J.Z. performed the security ink printing and imaging; S.A.T. carried out simulation work; W.R. conducted the surface modification; C.M. and F.W. built the optical testing system; J.Z. conducted the spectroscopic characterization; J.Z. and D.J. prepared the figures, data analysis, supplementary information sections, and wrote the manuscript with input from other authors.

\section{Competing interests}

The authors declare no competing financial interests.

\section{Additional information}

Supplementary information is available for this paper at https://doi.org/10.1038/ s41566-018-0108-5.

Reprints and permissions information is available at www.nature.com/reprints. Correspondence and requests for materials should be addressed to J.Z. or D.J.

Publisher's note: Springer Nature remains neutral with regard to jurisdictional claims in published maps and institutional affiliations. 


\section{Methods}

Upconversion nanoparticles synthesis. Typical $\beta-\mathrm{NaYF}_{4}$ nanoparticles. $\mathrm{NaYF}_{4}$ : $\mathrm{Yb}, \mathrm{Tm}$ (or Ho, Er) nanocrystals were synthesized using the organometallic method described previously. Briefly, $2.5 \mathrm{ml}$ of methanol solution of $\mathrm{LnCl}_{3} \bullet$ $6 \mathrm{H}_{2} \mathrm{O}(1.0 \mathrm{mmol}, \mathrm{Ln}=\mathrm{Y}, \mathrm{Yb}, \mathrm{Tm}$ (or Ho, Er)) together with $6 \mathrm{ml}$ oleic acid (OA) and $15 \mathrm{ml} 1$-octadecene (ODE) were added to a three-neck round-bottom flask. The resulting mixture was heated to $160^{\circ} \mathrm{C}$ under argon flow for $30 \mathrm{~min}$ to form a transparent yellowish solution. The solution was cooled down to room temperature, and $10 \mathrm{ml}$ of a methanol solution containing $0.148 \mathrm{~g} \mathrm{NH}_{4} \mathrm{~F}$ and $0.10 \mathrm{~g} \mathrm{NaOH}$ was added with vigorous stirring for $30 \mathrm{~min}$. Then, the slurry was slowly heated to $110^{\circ} \mathrm{C}$ for $30 \mathrm{~min}$ under vacuum to remove the methanol and small amounts of water. Next, the reaction mixture was protected by an argon atmosphere, quickly heated to $290^{\circ} \mathrm{C}$ or $300^{\circ} \mathrm{C}$, and maintained at that temperature for 1.5 hours. The solution was cooled down and the products were precipitated by the addition of ethanol, and centrifuged $(9,000 \mathrm{rpm})$ without size-selective fractionation. The final nanoparticles were re-dispersed in cyclohexane or dried at $60^{\circ} \mathrm{C}$ for 12 hours.

Sub-10 nm nanoparticles. In a typical experiment, $0.4 \mathrm{mmol} \mathrm{LnCl}_{3} \bullet 6 \mathrm{H}_{2} \mathrm{O}(\mathrm{Ln}=\mathrm{Y}$, $\mathrm{Yb}, \mathrm{Tm}$ ) with the molar ratio 50:49:1 was added to a $50 \mathrm{ml}$ flask containing oleic acid $(\mathrm{OA}, 6 \mathrm{ml})$ and 1-octadecene (ODE, $6 \mathrm{ml}$ ). The mixture was heated to $160^{\circ} \mathrm{C}$ under argon for $30 \mathrm{~min}$ to obtain a clear solution and then cooled down to about $70^{\circ} \mathrm{C}$, followed by the addition of $1.00 \mathrm{~g}$ of $\mathrm{NaOA}$ and $0.17 \mathrm{~g} \mathrm{NH}_{4} \mathrm{~F}$. After stirring for $30 \mathrm{~min}$, the solution was heated to $150^{\circ} \mathrm{C}$ under argon for $20 \mathrm{~min}$, and then the solution was further heated to $300^{\circ} \mathrm{C}$ for another $45 \mathrm{~min}$. Finally, the reaction solution was cooled down to room temperature, and nanoparticles were precipitated by ethanol and washed with cyclohexane, ethanol and methanol to get the $\mathrm{NaYF}_{4}$ : $\mathrm{Yb}$, Tm nanoparticles.

Core-shell nanoparticles. The shell precursor was first prepared by mixing $2.5 \mathrm{ml}$ of methanol solution of $\mathrm{LnCl}_{3} \bullet 6 \mathrm{H}_{2} \mathrm{O}(1.0 \mathrm{mmol}, \mathrm{Ln}=\mathrm{Y} / \mathrm{Yb} / \mathrm{Tm})$ together with $6 \mathrm{ml}$ oleic acid (OA) and $15 \mathrm{ml} \mathrm{1-octadecene} \mathrm{(ODE)} \mathrm{in} \mathrm{a} \mathrm{50-ml} \mathrm{flask} \mathrm{followed} \mathrm{by} \mathrm{heating}$ at $160^{\circ} \mathrm{C}$ under argon flow for $30 \mathrm{~min}$. After cooling down to room temperature, $10 \mathrm{~m}$ of a methanol solution containing $0.148 \mathrm{~g} \mathrm{NH}_{4} \mathrm{~F}$ and $0.10 \mathrm{~g} \mathrm{NaOH}$ was added with vigorous stirring for $30 \mathrm{~min}$. Then, the slurry was slowly heated to $110^{\circ} \mathrm{C}$ for $30 \mathrm{~min}$ under vacuum to remove the methanol and small amounts of water. To grow the shell layer, the preformed core nanoparticles were heated with $4.3 \mathrm{ml}$ of $\mathrm{OA}$ and $10.7 \mathrm{ml}$ of $\mathrm{ODE}$ to $300^{\circ} \mathrm{C}$ under argon, at which time the shell precursor was injected little by little. Each injection is composed of $0.15 \mathrm{ml}$ precursor which is maintained at a constant temperature for 3 minutes. The resulting nanoparticles were precipitated by the addition of ethanol, collected by centrifugation at $9,000 \mathrm{rpm}$ for $5 \mathrm{~min}$, washed with ethanol, and re-dispersed in cyclohexane or dried at $60^{\circ} \mathrm{C}$ for 12 hours.

Micro-rods. $\beta$ - $\mathrm{NaYF}_{4}$ micro-rods were hydrothermally prepared by using oleic acid as a stabilizing agent, $\mathrm{NaF}$ and $\mathrm{RE}\left(\mathrm{NO}_{3}\right)_{3}$ as precursors, and ethanol as a solvent, following Zhao et al. ${ }^{33}$. In a typical synthesis of $\beta-\mathrm{NaYF}_{4}$ rods, $\mathrm{NaOH}(0.7 \mathrm{~g}$, $17.5 \mathrm{mmol})$, oleic acid (90 wt.\%, 7.1 g, 22.6 mmol), and ethanol (10.0 g, $21.7 \mathrm{mmol})$ were mixed well at room temperature to obtain a white viscous solution. An aqueous solution of $\mathrm{NaF}(0.58 \mathrm{M}, 12.45 \mathrm{~mL}, 7.20 \mathrm{mmol})$ was added with vigorous stirring until a translucent solution was obtained. Then $50 \mathrm{~mol} \% \mathrm{Y}\left(\mathrm{NO}_{3}\right)_{3} \bullet 6 \mathrm{H}_{2} \mathrm{O}$, $1 \mathrm{~mol} \% \mathrm{Tm}\left(\mathrm{NO}_{3}\right)_{3} \bullet 6 \mathrm{H}_{2} \mathrm{O}, 49 \mathrm{~mol} \% \mathrm{Yb}\left(\mathrm{NO}_{3}\right)_{3} \bullet 6 \mathrm{H}_{2} \mathrm{O}$ in aqueous solution $(1.5 \mathrm{ml}$, $1.2 \mathrm{mmol}$ ) was poured into the above solution under vigorous stirring. After ageing for $20 \mathrm{~min}$, the mixture was transferred to a $50 \mathrm{ml}$ Teflon-lined autoclave, and heated at $230^{\circ} \mathrm{C}$ for $12 \mathrm{~h}$. The obtained rods were collected by centrifugation, washed with ethanol several times, and finally dried at $60^{\circ} \mathrm{C}$ for 12 hours.

Surface modification of nanoparticles. Preparation of DNA-capped nanoparticles. Typically, $50 \mu \mathrm{l}$ of $10 \mathrm{mg} \mathrm{ml}^{-1}$ nanoparticle suspension in cyclohexane was put into $400 \mu \mathrm{l}$ chloroform. $300 \mu \mathrm{l}$ of $5 \mu \mathrm{M}$ DNA water solution was added to the nanoparticle suspension. A gentle shake $(600 \mathrm{rpm})$ followed, and after 2 hours the nanoparticles were transferred from chloroform to the water phase.

Preparation of citrate-capped nanoparticles. Typically, $50 \mu \mathrm{l}$ of $10 \mathrm{mg} \mathrm{ml}^{-1}$ nanoparticle suspension in cyclohexane was put into $400 \mu \mathrm{l}$ chloroform. $300 \mu \mathrm{l}$ as purchased SSC Buffer $(20 \times$ concentrate, Sigma, SRE0068) was added to the nanoparticle suspension. A gentle shake $(600 \mathrm{rpm})$ followed and, after 2 hours, the nanoparticles were transferred from chloroform to the water phase.

Heat-treatment of nanoparticles. The dried nanoparticles were kept in a corundum crucible and put in a heat-treating furnace. The nanoparticles were treated in the atmospheric environment at $773 \mathrm{~K}$ for 1 hour with a heating rate of $5^{\circ} \mathrm{C} \mathrm{min}^{-1}$ before being cooled inside the furnace to room temperature.

General materials characterization. $X R D$. Powder X-ray diffraction (XRD) data were recorded on a Bruker D8 Discover diffractometer with a slit of $0.02^{\circ}$ at a scanning speed of $2^{\circ} \mathrm{min}^{-1}$ using $\mathrm{Cu} \mathrm{K} \alpha$ radiation $(\lambda=1.5406 \AA)$.
TEM. Transmission electron microscope (TEM) measurements were performed using a FEI T20 Tecnai instrument. The samples for TEM analysis were prepared by placing a drop of a dilute suspension of nanoparticles onto carbon-coated copper grids.

SEM. Scanning electron microscopy (SEM) was performed on a SU8010 fieldemission scanning electron microscope (Hitachi) operated at $1 \mathrm{kV}$. The samples for SEM analysis were prepared by placing a drop of a dilute suspension of nanoparticles onto a silicon wafer.

Raman. Raman data were recorded on a Renishaw inVia (Gloucestershire, UK) with a $532 \mathrm{~nm}$ excitation source. The samples for Raman analysis were prepared by placing a small pile of dried nanoparticles flat on a glass slide.

FTIR. Fourier transform infrared (FTIR) spectroscopy spectra were obtained on a Varian 3100 FT-IR spectrometer.

Optical characterization. Upconversion emission spectra were recorded using a home-built spectroscopic system. A power-tunable $980 \mathrm{~nm}$ continuous wave diode laser was used as the excitation source, which passed through an objective lens, and then was focused to a size-controllable spot covering the powder sample. The dried powder samples were located in a copper holder, which was mounted on a $\mathrm{XYZ}$ stage to ensure the appropriate position. The temperature of the sample was controlled by a heating system assembled with a metal ceramic heater (HT24S2, Thorlabs) and a heater controller (TC200-EC, Thorlabs). Emission spectra were collected by another objective lens, and then detected by a spectrometer (Shamrock 193i Spectrograph, Andor) equipped with an EMCCD detector (iXon Ultra, Andor).

Details of the ab initio calculations. The equilibrium structure of the adsorption of oleic acid on the $\beta-\mathrm{NaYF}_{4}$ is calculated in vacuum using density functional theory (DFT) within the generalized gradient approximation (GGA) of Perdew, Burke and Ernzerfof $(\mathrm{PBE})^{34}$. The valence electrons are separated from the core by means of the projector-augmented wave pseudopotentials (PAW) ${ }^{35}$ as implemented in the VASP package, version 5.4.1 $1^{36}$. The energy cut-off for the plane wave basis set is $500 \mathrm{eV}$, and the energy tolerance is $10^{-5}$ to ensure accuracy of the calculations. The lattice constants of the $\beta-\mathrm{NaYF}_{4}$ unit cell have been obtained as $a=6.0 \AA$, $c=3.61 \AA$, which is in good agreement with the experimental values of $a=5.96 \AA$, $c=3.53 \AA$ (ref. ${ }^{37}$ ). In this calculation, oleic acid $\left(\mathrm{OA}^{-}\right)$is modelled by considering the $\mathrm{CH}_{3} \mathrm{CO}_{2}^{-}$group of the molecule. The size of the supercells used for the $\mathrm{OA}^{-}$ interaction with the surface are $10.39 \AA \times 12.0 \AA \times 30.0 \AA$ for the $(001)$ facet and $12.0 \AA \times 14.41 \AA \times 25 \AA$ for the (100) facet. For the structural energy minimization, the internal coordinates are allowed to relax until all of the forces are less than $0.01 \mathrm{eV} \AA^{-1}$. A vacuum region of $\sim 17 \AA$ is added between the periodic images to avoid interactions between them. For the vibrational frequency calculations, the harmonic approximation is applied, in which we allow only the $\mathrm{OA}^{-}$atoms to move in the $\mathrm{z}$-axis direction.

UCNP printing. $\mathrm{NaYF}_{4}: \mathrm{Yb}^{3+}-\mathrm{Tm}^{3+}$ and $\mathrm{NaYF}_{4}: \mathrm{Yb}^{3+}-\mathrm{Er}^{3+} \mathrm{UCNP}$ prepared in cyclohexane at concentrations of $12 \mathrm{mg} \mathrm{ml}^{-1}$ and $3 \mathrm{mg} \mathrm{ml}^{-1}$ respectively were used for printing. Prior to printing, the solutions were sonicated for 10 minutes. A modified HP deskjet 3632 inkjet printer was used to print the UCNP inks. The UCNP inks were repeatedly printed up to 40 times onto paper, with each UCNP ink being separately printed through a separate black ink cartridge. Images of the printed pattern under external $980 \mathrm{~nm}$ laser excitation at a power density of $0.7 \mathrm{~W} \mathrm{~cm}^{-2}$ were taken via a Canon EOS 70D camera with a Macro lens and an $842 \mathrm{~nm}$ short-pass filter attached. Images were taken using an exposure time of 60 seconds at room temperature and at $453 \mathrm{~K}$.

Data availability. The data that support the plots within this paper and other findings of this study are available from the corresponding author upon reasonable request.

\section{References}

33. Zhang, F. et al. Shape, size, and phase-controlled rare-earth fluoride nanocrystals with optical up-conversion properties. Chem. Eur. J. 15, 11010-11019 (2009).

34. Perdew, J. P., Burke, K. \& Ernzerhof, M. Generalized gradient approximation made simple. Phys. Rev. Lett. 77, 3865-3868 (1996).

35. Blöchl, P. E. Projector augmented-wave method. Phys. Rev. B 50, 17953 (1994).

36. Kresse, G. \& Furthmüller, J. Efficient iterative schemes for ab initio total-energy calculations using a plane-wave basis set. Phys. Rev. B 54, 11169-11186 (1996).

37. Liu, D. et al Three-dimensional controlled growth of monodisperse sub-50 $\mathrm{nm}$ heterogeneous nanocrystals. Nat. Commun. 7, 10254 (2016). 